\title{
Decision support, Knowledge Representation and Management: A broad methodological
}

\section{spectrum}

\author{
Findings from the Decision Support, Knowledge \\ Representation and Management
}

\author{
B. Brigl, Managing Editor for the IMIA Yearbook Section on Decision Support, Knowledge \\ Representation and Management. \\ University of Leipzig, Institute of Medical Informatics, Statistics and Epidemiology, Leipzig, Germany
}

\begin{abstract}
Summary
Objectives: To summarize current excellent research in the field of decision support, knowledge management and representation. Methods:Synopsis of the articlesselected for the IMIA Yearbook 2006.

Results: Decision Support, Knowledge Representation and Management covers a broad spectrum of methods applied to a variety of medical problems and domains. Some particularly interesting and current topics were picked for the IMIA Yearbook 2006: the importance of ontologies for systematic system engineering of decision support systems, syndromic surveillance based on natural language processing, the evaluation of large semantic networks, and a comprehensive ontology for a randomised controlled trial database to support evidence-based practise. Conclusions: The best paper selection shows that methods for decision support, knowledge representation and management can decisively contribute to the solution of many different medical problems, but al so that there is still a lot of exiting research to be done

HauxR, Kulikowski C, editors. IMIA Yearbook of Medical Informatics 2006. Methods InfMed 2006; 45 Suppl I: S87-3.
\end{abstract}

\section{Keywords}

Medical Informatics, International Medical Informatics Association, Yearbook, knowledge management, knowledge representation, decision support, ontologies, natural language processing

\section{Introduction}

Decision Support, Knowledge Representation and Management comprises a broad spectrum of methodological approaches like natural language processing [1], ontologies [2], knowledge acquisition, knowledge representation, and reasoning [3], [4] as basis to build or expand application systems which support, facilitate, and improve diagnostic, therapeutic and prognostic medical decisions in various medical domains. The development of suitable methods [5] is important along with the evaluation of their correctness and adequacy [6].

\section{Best Paper Selection}

The best paper selection of articles for the section 'Decision Support, Knowledge Representation and Management' in the IMIA Yearbook 2006 reflects this methodological diversity, which is also expressed in previous yearbooks [7], [8].

As a result of a comprehensive reviewing process, five excellent articles were selected from four international peer reviewed journals in the fields of medical informatics. Table 1 presents the selected papers. A brief content sum- mary of the selected best papers can be found in the appendix of this report.

\section{Conclusions and Outlook}

The best paper selection for the Yearbook section 'decision support, knowledge representation and management' shows that research is actively done in many different areas of interest. [9] and [10] show how important ontologies are for the successful implementation of clinical decision support systems, as basis for integrated software architectures including knowledge base, database and user interface. However, these papers also indicate that we are still far away from real functional integration with hospital-wide clinical workstations [11]. The relevance of natural language processing to detect disease outbreaks from a large amount of patient data at an early stage is demonstrated in [12], which is an important contribution to the field of syndromic surveillance. In [13] the problem of knowledge maintenance in large semantic networks is addressed. An ontology as basis for a randomized controlled trial database to support evidence-based practice is presented in [14]. On the one hand, the selected papers show that methods for 
Table 1 Best paper selection of artidesfor the IMIA Yearbook of Medical Informatics2006 in the section 'Decision Support, Knowledge Representation and Management'. The artides are listed in alphabetical order of the first author's surname.

\section{Section}

Decision Support, Knowledge Representation and Management

- Chapman W W, Christensen WL, Wagner MM, Haug PJ, Ivanov 0, Dowling JN, Olszewski RT. Classifying free-text triage chief complaints into syndromic categories with natural language processing. Artif Intell Med 2005; 33(1): 31-40.

- Garde S, Baumgarten B, Basu O, Graf N, Haux R, Herold R, Kutscha U, Schilling F, Selle B, Spiess C, Wetter T, Knaup P. A meta-model of chemotherapy planning in the multi-hospital/multi-trial-center-environment of pediatric oncology. Methods Inf Med 2004; 43(2): 171-83.

- Michalowski W, Slowinski R, Slowinski R, Wilk S, Farion KJ, Pike J, Rubin S. Design and development of a mobile system for supporting emergency triage. Methods Inf Med 2005; 44(1): 14-24.

- Shapiro LG, Chung E, Detwiler LT, Mejino JLV, Agoncillo AV, BrinkleyJF, Rosse C. Processes and problems in the formative evaluation of an interface to the Foundational Model of Anatomy knowledge base. J Am Med Inform Assoc 2005; 12(1): 35-46.

- Sim I, Olasov B, Carini S. An ontology of randomized controlled trials for evidence-based practice: content specification and evaluation using the competency decomposition method. J Biomed Inform 2004; 37(2): 108-19.

decision support, knowledge representation and management can decisively contribute to the solution of many different medical problems. On the other hand, they indicate that a lot of exiting research still needs to be done [17]. Up-to-date information about current and future issues of the IMIA Yearbook is available at http://iig.umit.at/yearbook/

\section{Acknowledgement}

We greatly acknowledge the support of Martina Hutter and of the reviewers in the selection process of the IMIA Yearbook.

\section{References}

1. Friedman C, Hripcsak G. Natural Language processing and its future in medicine. Acad Med 1999; 74(8): 890-5.

2. Jiang G, Ogasawara K, Endoh A, Sakurai T: Contextbased ontology building support in clinical domains using formal concept analysis. Int J Med Inform 2003 Aug;71(1): 71-81.

3. Volot F, Joubert M, Fieschi M. Review of biomedical knowledge and data representation with conceptual graphs. Methods Inf Med 1998 Jan; 37(1): 86-96.

4. Augusto JC. Temporal reasoning for decision support in medicine. Artif Intell Med 2005 Jan; 33(1): 1-24.

5. Long WJ. Medical informatics: reasoning methods. Artif Intell Med. 2001 Aug; 23(1): 71-87.

6. Garg AX, Adhikari NK, McDonald H, RosasArellano MP, Devereaux PJ, Beyene J, et al. Effects of computerized clinical decision support systems on practitioner performance and patient outcomes: a systematic review. JAMA 2005 Mar 9; 293(10): 1223-38.

7. Knaup P, Ammenwerth E, Brandner R, Brigl B, Fischer G, Garde S, et al. Towards clinical bioinformatics: advancing genomic medicine with informatics methods and tools. Methods Inf Med 2004; 43: 302-7.

8. Bott OJ, Ammenwerth E, Brigl B, Knaup P, Lang E, Pilgram R, et al. The challenge of ubiquitous computing in health care: technology, concepts and solutions. Findings from the IMIA Yearbook of Medical Informatics 2005. Methods Inf Med 2005; 44: 473-9.

9. Garde S, Baumgarten B, Basu O, Graf N, Haux R, Herold R, et al. A meta-model of chemotherapy planning in the multi-hospital/multi-trial-centerenvironment of pediatric oncology. Methods Inf Med 2004; 43(2): 171-83.

10. Michalowski W, Slowinski R, Slowinski R, Wilk $\mathrm{S}$, Farion KJ, Pike J, et al. Design and development of a mobile system for supporting emergency triage. Methods Inf Med 2005; 44(1): 14-24.

11. Haug PJ, Rocha BH, Evans RS. Decision support in medicine: lessons from the HELP system. Int J Med Inform 2003 Mar; 69(2-3):273-84.

12. Chapman W W, Christensen WL, Wagner MM, Haug PJ, Ivanov O, Dowling JN, Olszewski RT. Classifying free-text triage chief complaints into syndromic categories with natural language processing. Artif Intell Med 2005; 33(1): 31-40.

13. Shapiro LG, Chung E, Detwiler LT, Mejino JLV, Agoncillo AV, Brinkley JF, et al. Processes and problems in the formative evaluation of an interface to the Foundational Model of Anatomy knowledge base. J Am Med Inform Assoc 2005; 12(1): 35-46.

14. Sim I, Olasov B, Carini S. An ontology of randomized controlled trials for evidence-based practice: content specification and evaluation using the competency decomposition method. J Biomed Inform 2004; 37(2): 108-19.

15. Bravata DM, McDonald KM, Smith WM, Rydzak C, Szeto H, Buckeridge DL, et al. Systematic review: surveillance systems for early detection of bioterrorism-related diseases. Ann Intern Med 2004 Jun 1; 140(11): 910-22.

16. Cimino JJ, Min H, Perl Y. Consistency across the hierarchies of the UMLS Semantic Network and Metathesaurus. J Biomed Inform 2003 Dec; 36(6): 450-61.

17. Hasman A, Safran C, Takeda H. Quality of health care: informatics foundations. Methods Inf Med 2003; 42(5): 509-18.

Correspondence to:

Dr. Birgit Brigl

Kapersburgstr. 40

61381 Friedrichsdorf

Germany

E-mail: birgit.brigl@ t-online.de

Appendix: Content Summaries of Selected Best Papers, Sedion Deásion Support, Knowledge Representation and Management*

\section{Chapman W W, Christensen WL, Wagner MM, Haug PJ, I vanov 0, Dowling JN, Olszewski RT. \\ Classifying free-text triage chief complaints into syndromiccategories with natural language processing.}

Artif Intell Med 2005; 33(1): 31-40

Chapman et al. ([12]) are engaged in a very current and important field of research; the syndromic surveillance of bioterroristic [15] or naturally-occurring disease outbreaks. They argue that free-text triage chief complaints are the earliest data on hand in a hospital information system. Consequently they apply methods for natural language processing to detect disease outbreaks. As basis they use an adapted version of the Medical Probabilistic Language

\footnotetext{
* The complete papers can be accessed in the Yearbook's full electronic version, provided that permission has been granted by the copyright holder(s)
} 
Understanding System (M+) working with a Bayesian network-based semantic model. After a training phase comprising 4700 chief complaints they evaluated the accuracy of classifying triage chief complaints into eight previously defined syndromic categories by comparing the results of $\mathrm{M}+$ with those of a gold standard physician. They conclude that a natural language processing text classifier is an effective method to support syndromic surveillance.

\section{Garde S, Baumgarten B, Basu 0, Graf N, Haux R, Herold R, Kutscha U, Schilling F, Selle B, Spiess C, Wetter T, Knaup P.}

A meta-model of chemotherapy planning in the multi-hospital/multi-trial-centerenvironment of pediatric oncology

\section{Methods Inf Med 2004; 43(2): 171-83}

Garde et al. ([9]) show the importance of ontologies for the development of decision support systems on the example of chemotherapeutic planning in pediatric ontology. ChemoMM - an ontology for chemotherapy planning is the result of a long lasting evolutionary development process based on evolutionary prototyping, software engineering techniques and grounded theory, which lead to a stable, user-validated ontology. ChemoMM is basis for two application systems which support the knowledge-acquisition process for chemotherapy plans as well as protocol-based decision support. They were used in clinical routine in about 30 hospitals over many years without reported calculation errors. ChemoMM or parts of it may easily be adapted to other oncological domains as basis for chemotherapy planning systems.

\section{Michalowski W, Slowinski R, Slowinski R, WilkS, Farion KJ, Pike J, Rubin S.}

Design and development of a mobile system for supporting emergency triage. Methods Inf Med 2005; 44(1): 14-24.

Another excellent example for a patient-specific clinical decision support system is given in [10]. Michalowski et al. designed, developed and evaluated a mobile consultant system for supporting emergency triage (MET) in the field of acute pain. The main focus was on the integration of MET with the physician's workflow, and with the electronic patient record system. The knowledge base, as well as the user interface, are based on a specific domain ontology. The knowledge base consists of decision rules created from historical patient data. Because of the weak connectivity situation in an emergency department, they used an extended clientserver-architecture, where the handheld client computer can run some functions of the server if there is no connection available. The clinical evaluation could show that the system fits well into the emergency department workflow.

\section{Shapiro LG, Chung E, Detwiler LT, Mejino JLV, Agoncillo AV, Brinkley JF, Rosse C.}

Processes and problems in the formative evaluation of an interface to the Foundational Model of Anatomy knowledge base.

\section{JAm Med Inform Assoc 2005; 12(1): 35-46}

The Digital Anatomist Foundational Model of Anatomy is a large semantic network of more than 100,000 anatomical terms and about 1.6 million structural relationships, which is used as knowledge source by anatomists and students. In such a large knowledge base, the evaluation for accuracy and comprehensiveness is a special challenge. For this, Shapiro et al. ([13]) developed a generic query interface focusing especially on the relationships. This query interface allows domain experts to enter both simple and relatively complex queries concerning the structural relationships among anatomical entities of the human body as a starting point for the maintenance of the knowledge base. With minor modifications, this tool may also be used for the evaluation of other large semantic networks [16].

\section{Sim I, Olasov B, Carini S. An ontology of randomized controlled trials for evidence- based practice: content specification and evaluation using the competency decomposition method.}

\section{J Biomed Inform 2004; 37(2): 108-19.}

Medical research produces about 10,000 new randomized controlled trials (RCT) each year. It is difficult to provide this evidence-based knowledge to clinicians or practitioners. To build up a RCT knowledge base, Sim et al. ([14]) developed an ontology using the competency decomposition method. With this method a top-level task - in this case the task of systematic reviewing - was decomposed into a set of subtasks,and the methods by which each subtask is supported, and the information items necessary to carry out the subtasks were identified. The resulting RCT schema contains 188 hierarchically structured classes and 601 attributes regarding details about administration, design, execution and results of RCT. In a first step, the RCT schema was used to completely capture 11 trials , and partly capture 13 others. The results show that, with some minor limitations, the RCT schema is well suited for the task of systematically reviewing RCTs. 